\title{
História, literatura e criminalidade: um olhar sobre 0 crime da Galeria de Cristal, de Boris Fausto
}

History, literature and criminality: a view above the book O crime da Galeria de Cristal, by Boris Fausto

Taynara Leszczynki Maria Salete Borba 
O livro O crime da Galeria de Cristal: e os dois crimes da mala São Paulo, 19081928 foi publicado em 2019, pela editora Companhia das Letras e é de autoria de Boris Fausto, historiador, professor aposentado do Departamento de Ciência Política da Universidade de São Paulo (USP) e membro da Academia Brasileira de Ciências (ABC). Nascido em 1930, em São Paulo, onde ainda reside, o pesquisador tornou-se uma grande referência em estudos de história que envolvam a criminalidade. Fausto também é autor de outros livros, como $O$ crime do restaurante chinês: carnaval, futebol e justiça na São Paulo dos anos 30 (2009), Negócios e ócios: histórias da migração (1999) e A revolução de 1930: historiografia e história (1970).

Entender a história do país de forma não linear por meio da criminalidade, observando como cada época reage a cada caso e o contexto nos quais estes se inserem é o que o autor anseia em seu trabalho mais recente, O crime da Galeria de Cristal (2019). O livro possui 255 páginas e, a partir de uma divisão em duas seções, apresenta três histórias que se assemelham ao gênero textual conto. Na primeira parte, há todo o relato e o estudo sobre o crime que leva o mesmo título do livro e, na segunda, acerca dos dois "crimes da mala", os quais o autor mantém com os mesmos nomes pelos quais ficaram popularmente conhecidos: "O primeiro crime da mala" e "O segundo crime da mala". Ambos os casos ocorreram em São Paulo, no início do século XX e chocaram todo o país na época, tanto por serem bastante impiedosos, inusitados e com personagens peculiares, quanto pelo sensacionalismo da impressa brasileira que começava a se fundar no âmbito dos atos criminosos, tendo como veículo principal o jornal impresso.

A partir dos recortes de tais jornais, o autor mostra como era o ponto de vista, de forma geral, da sociedade paulistana do século XX, estabelecendo conexões dos crimes que selecionou com o contexto da época, realçando o que estava em pauta naquele período, desde questões econômicas e políticas quanto culturais. Não obstante, ao mencionar a modernização que o país almejava e aos poucos estava alcançando, ainda dá ênfase aos teatros, cinemas e à música da época que, tendo como referência a cultura europeia, conquistavam cada vez mais público, principalmente, a burguesia, mais interessada em adquirir status do que conhecimento cultural.

O livro é repleto de fotografias antigas dos lugares mais importantes, tanto culturalmente quanto no que condiz à modernização para esse período, tais como as sedes dos jornais de maior renome, o Teatro Colombo, Cine Bijou Theatre, a Estação Norte (de trens), o Bonde de Bom Retiro e, juntamente a isso, os locais de interesse à investigação dos crimes, como casas e pensões onde as vítimas e suspeitos haviam morado, espaços onde os delitos ocorreram, lugares públicos próximos, entre outros. A maior parte dessas imagens foi retirada de jornais. Bem como, ilustrações, charges, 
trocadilhos e piadas acerca dos casos, arquivos estes que suportam a ideia apontada pelo autor de que os crimes sensacionais tomavam a atenção da população acima de qualquer outra notícia.

Os jornais mais mencionados pelo historiador ao decorrer do livro são $O$ Estado de São Paulo, Correio Paulistano e O commercio de São Paulo ${ }^{1}$, os quais recebem várias críticas referentes ao modo sensacionalista pelo qual retratavam e romantizavam os casos. Fausto (2019) enfatiza que os eventos noticiados por tais veículos de imprensa sempre tomavam as primeiras páginas, pois o crime é interessante apenas enquanto é recente, portanto, em matéria de criminalidade, a circulação de folhetins era algo bastante recorrente, dada a influência francesa da época, também chamados fait divers.

Como visto, a crítica social é algo muito recorrente na escrita do historiador. Seu olhar preciso perpassa pelos mais diversos contextos. Nota-se também que o autor não se prende a uma ordem cronológica dos fatos, tanto na ordem pela qual os casos estão postos no livro quanto pelos acontecimentos de cada caso.

Apesar de partir de uma escrita anacrônica, o autor tem o cuidado de ir situando o leitor ao contexto de cada história. Por exemplo, informa que "O primeiro crime da mala" e "O crime da Galeria de Cristal" estão localizados no famoso período no Brasil, de grande influência francesa, intitulado Belle époque. Através de tais apontamentos, é pertinente realçar a maneira clara, concisa e dinâmica pela qual a sua escrita se dá.

O livro conta uma apresentação escrita pelo músico, compositor e escritor brasileiro Tony Bellotto, conhecido, principalmente, por ser o guitarrista da banda de rock nacional "Titãs". Em sua introdução, o autor discorre acerca da habilidade de Fausto em trazer crimes factuais para a literatura de modo que mantém a seriedade e a imparcialidade tão requisitada à figura do historiador, mas que ainda assim constrói uma atmosfera noir, à moda Edgar Allan Poe.

É possível dizer que tal camada de suspense que se instaura no livro se deve, sobretudo, à colagem feita pelo autor com fotografias e recortes de jornais do século $\mathrm{XX}$, sobre os crimes selecionados, que também fortalecem uma atmosfera vintage. Juntamente a uma escrita bastante sucinta e ao mesmo tempo impactante, uma vez que se refere a crimes brutais, O crime da Galeria de Cristal (2019) faz uma revisão histórica de como a criminalidade impactou a sociedade e a imprensa da época.

Os crimes pesquisados, contados e analisados pelo autor aconteceram, respectivamente, nos anos de 1908 (O primeiro crime da mala), 1909 (O crime da Galeria de Cristal) e 1928 (O segundo crime da mala). O primeiro apresentado no livro, ainda que não tenha sido o primeiro a acontecer, foi " $\mathrm{O}$ crime da Galeria de

$1 \mathrm{O}$ autor mantém a grafia da época. 
Cristal", o assassinato de Arthur Malheiros, cometido por uma mulher com a qual ele teve um envolvimento amoroso na juventude, Albertina Bonilha, e presenciado pelo atual marido dela, Eliziário Bonilha. Esse delito ficou conhecido como um "crime de honra" pela população e dividiu opiniões tanto do povo quanto da imprensa que ora defendiam a atitude de Albertina ora a acusavam. Isso porque assim que a autora do crime engravidou, na juventude, foi logo abandonada pelo pai da criança, Arthur Malheiros.

Com base nesse acontecimento, árduas discussões acerca do tratamento às mulheres e seus papéis sociais foram trazidas à tona pelos jornais daquele ano e, posteriormente, retomadas pelo autor a partir da maneira pela qual a sociedade condenava a assassina muito mais por ser uma mãe solteira que entregou o filho para a adoção do que por ser uma assassina. Outro aspecto de interesse nessa história é que uma revista da época, chamada Revista Careta, em sua edição de 6 de março de 1909, chegou a publicar uma foto do falecido ainda no necrotério. Novamente, o historiador faz uma referência crítica ao sensacionalismo da imprensa que, muitas vezes, para chamar mais atenção da população, mas também a fim de se sobressair diante da concorrência, ultrapassava os limites, ignorando os direitos humanos e o respeito às vítimas e aos familiares.

O segundo caso apresentado no livro é "O primeiro crime da mala", o qual consiste em um assassinato de um empresário pelo seu funcionário. A motivação teria sido um amor secreto nutrido pelo empregado em relação à esposa de seu chefe, que não se sabe se era correspondido ou não, assim, ele tentou se livrar do marido. Nesse crime em questão, Fausto (2019) aponta como a possibilidade de um romance proibido, ainda que não fora comprovado o envolvimento da viúva, Carolina Farhat, com o empregado, Michel Trad, despertou na população certa empatia pelo assassino, a qual é contestada arduamente pelo autor, que discorre acerca da hipocrisia que circula a respeito do juízo de valor no entorno daquilo que pode ser considerado criminoso ou não.

Enquanto possível história romântica, o caso servia como um espetáculo, o qual era apresentado pela imprensa. E a crítica consiste, justamente, nisso. Um veículo de informação, que deveria noticiar a criminalidade de forma imparcial, neutra e séria, transforma-o em um romance, com o claro intuito de entreter e divertir, em vez de informar.

O terceiro e último caso do livro é "O segundo crime da mala", vinte anos o separam do primeiro e, assim, na introdução dessa história, o autor dá destaque às mudanças ocorridas em São Paulo nesse espaço de tempo, contudo, algumas coisas 
aparentam não mudar, como a violência. Novamente, a motivação do crime é passional, dessa vez, o marido assassina a esposa após uma discussão doméstica, esquarteja-a e, pondo-a em uma mala, tenta desfazer-se do corpo.

Giuseppe Pistone, o novo assassino da mala, não despertou na população a mesma empatia que seu antecessor, Michel Trad, de início, como aponta o autor, até o momento em que começou a aluir a uma traição por parte da falecida esposa, então, muitos posicionaram-se a favor do criminoso, realçando que um adultério justificaria o ato. Fausto (2019) salienta que os crimes que provocam uma divisão de opiniões tendem a ter ainda mais visibilidade. E, da mesma forma vista em 1908, o palácio onde ocorriam os julgamentos lotou-se de pessoas curiosas para assistir à sentença. Além da questão do feminicídio, adentrando debates acerca da violência doméstica, o autor também traz à tona outro assunto pertinente: a imigração, uma vez que tanto o assassino quanto a vítima, Maria Mercedes Feá, vieram da Itália para o Brasil.

Nesse caso, há várias referências ao primeiro crime da mala, como forma do autor enfatizar que o imaginário da população da época era mais duradouro se posto em contraste com o de hoje em dia em que, devido à tecnologia virtual, recebemse várias informações instantaneamente; mas, que não são armazenadas na memória coletiva.

Ambos os crimes, portanto, continuavam bastante vivos na lembrança popular. Entre as razões que fortalecem esse não esquecimento está o alarme feito pela mídia da época em cima dos casos. O que, como foi visto, apesar de ocorrer hoje em dia, não se perdura pela quantidade de informações que são lançadas ao espectador. Ao final, o autor reitera que outros crimes da mala vieram a acontecer posteriormente, no entanto, jamais foram memoráveis como esses dois, que entraram de certa forma para o folclore brasileiro, sendo mencionados nos jornais e também no cinema e na literatura.

Outro aspecto interessante é que, muito embora Boris Fausto não faça nenhuma menção ao escritor, jornalista, cineasta, e também paulista, Valêncio Xavier ${ }^{2}$, o seu livro Crimes à moda antiga (2004) dialoga muito bem com O crime da Galeria de Cristal (2019), uma vez que segue essa mesma técnica da colagem, de retirar histórias reais do jornal e trazê-las para a ficção. No livro de Xavier (2004) há oito contos, baseados em casos bastante cruéis e curiosos que aconteceram no Brasil em meados do século XX e, além dessa semelhança, entre tais narrativas estão os três crimes trabalhados por Fausto (2019), o da Galeria de Cristal e os dois crimes da mala.

2 XAVIER, Valêncio. Crimes à moda antiga: contos verdade, 2004. 
Por fim, registra-se que esse livro é de interesse acadêmico, uma vez que, além de trabalhar com a história, também adentra o contexto da literatura policial, rompendo com o seu modelo usual à moda de Edgar Allan Poe, Agatha Christie e Conan Doyle, por exemplo, e propondo uma nova forma de leitura, a partir de fragmentos. A técnica da colagem, própria da arte moderna, estende-se, portanto, na contemporânea.

\section{Referências Bibliográficas}

FAUSTO, Boris. O crime da Galeria de Cristal: e os dois crimes da mala São Paulo, 1908-1928. São Paulo: Companhia das Letras, 2019.

XAVIER, Valêncio. Crimes à moda antiga: contos verdade. São Paulo: Publifolha, 2004.

Submissão: 06/05/2020

Aceite: $28 / 07 / 2020$

https://doi.org/10.5007/2176-8552.2020.e73297

Esta obra foi licenciada com uma Licença Creative Commons Atribuição-NãoComercial 4.0 Internacional. 